Article

\title{
Experimental and Numerical Study on the Thermal Performance of a Water/Steam Cavity Receiver
}

\section{Nan Tu, Jinjia Wei * and Jiabin Fang}

State Key Laboratory of Multiphase Flow in Power Engineering, Xi'an Jiaotong University, Xi'an 710049, China; E-Mails: tu.nan@ stu.xjtu.edu.cn (N.T.); jiabinfang@qq.com (J.F.)

* Author to whom correspondence should be addressed; E-Mail: jjwei@ mail.xjtu.edu.cn; Tel.: +86-029-82664462; Fax: +86-029-82669033.

Received: 26 September 2012; in revised form: 7 December 2012 / Accepted: 24 January 2013 / Published: 25 February 2013

\begin{abstract}
An experimental platform was designed and built for testing the thermal performance of a water/steam cavity receiver. The experimental platform was utilized to investigate the start-up performance and operation characteristics of the receiver. The electrical heating mode was chosen to simulate the non-uniform distribution of heat flux on the surface of absorber tubes inside the cavity. During start-up the temperature rise rate and the mass flow rate are considered as control variables. A couple of start-up curves under different working pressures were finally obtained. The results showed that the receiver performed at relatively low thermal efficiencies. The main reason for the low thermal efficiency was attributed to the low steam mass flow rate, which causes a high proportional heat loss. In order to study the relationship between thermal efficiency and mass flow rate, a computational model for evaluating the thermal performance of a cavity receiver was built and verified. This model couples three aspects of heat transfer: the radiative heat transfer inside the receiver, the flow boiling heat transfer inside the absorber tubes and the convection heat transfer around the receiver. The water/steam cavity receiver of the experimental platform was studied numerically. The curve of thermal efficiency versus mass flow rate was obtained to show that the thermal efficiency increases with increasing mass flow rate within a certain range, and the increase is more remarkable at low mass flow rates. The purpose of the present study was to determine an appropriate mass flow rate for the receiver of the experimental platform to ensure its efficient operation.
\end{abstract}

Keywords: cavity receiver; thermal performance; start-up; mass flow rate 


\section{Introduction}

As problems of energy shortage and environment pollution become more and more serious, clean and renewable energy has been of particular concern and studied all over the World. Solar energy is a kind of non-polluting renewable energy and can be obtained for free, so it has been used more and more extensively. The utilization of solar energy for power generation is usually realized by adopting three primary technologies. Wang [1] reported that the tower type solar power technology has better commercial prospects than those of trough type and dish type solar power technologies in respect of large-scale power generation. The equipment cost of tower type solar power system is much lower than that of dish type and slightly higher than that of trough type, and the equipment cost will be further reduced in larger scale power generation. The equipment cost of tower type systems mainly consists of the costs for the heliostat field and the receiver, and the cost of the receiver accounts for $20 \%$ of the total equipment cost.

The solar receiver is a key component, which transforms light into heat in a tower type solar power system. The performance of a solar receiver is in direct relation to the efficiency of the whole power generation system. One possible configuration usually used in tower type solar power system is the cavity receiver because of its large surface area and low thermal loss compared to an external receiver. There is usually an aperture on the front surface of the cavity receiver, through which sunlight concentrated by a heliostat field projects onto the surface inside the cavity. Meanwhile, the existence of the aperture causes unavoidable energy losses, including radiative heat loss and convective heat loss, so most studies on the thermal performance of solar cavity receivers focus on thermal efficiency and thermal loss. Clausing [2] presented an analytical model for estimating the convective heat loss of a large open cubical cavity receiver. The model was refined by including the aperture area and was later validated with experimental data [3]. Behnia and Reizes [4] have studied combined radiation and natural convection in a rectangular cavity filled with a non-participating fluid. One wall of the cavity is an isothermal heat source while the opposite wall is allowed to transfer heat to the surroundings by convection and radiation. The two end walls are adiabatic. They found that external convection weakens the internal circulation, and radiation strengthens the flow. Ramesh and Venkateshan [5] have led an experimental study on natural convection and surface radiation in an air-filled cubical enclosure. The result of this study shows that the heat transfer by convection and radiation between high emissive walls is about twice as high as that between low emissive ones, and the effect of radiation is less significant. Taumoefolau et al. [6] conducted some experimental studies on the natural convective heat loss of the open cavity receiver by using electrical heating as a heat source. They found the relationship between the natural convective heat loss and the inclination angles which vary from $-90^{\circ}$ (cavity facing vertically upward) to $+90^{\circ}$ (cavity facing straight down). They also carried out numerical simulation of the convective heat loss with CFD. The numerical results show good agreement with the experimental data. A 2-D model was applied by Sendhil Kumar and Reddy [7] to investigate the natural convective heat loss from a modified open cavity receiver. Based on the assumption of uniform solar flux distribution in the central plane of receiver, the convective heat loss variation with the inclination was estimated. They found that the convective heat loss reaches the maximum value at $0^{\circ}$ (cavity aperture facing sideways) and decreases monotonically with the increasing inclination angle up to $90^{\circ}$ (cavity aperture facing down). Le Quere et al. [8,9] 
experimentally and numerically investigated thermal driven laminar natural convection in an open cubical cavity with isothermal sides, one of which faces the opening. Primitive variables and finite difference expressions were adopted to solve the problems of large temperature and density variations. They found that the convective heat loss is strongly dependent on the cavity inclination and correlations for each inclination were established. Reynolds et al. [10] used an experimental technique to investigate the heat losses from the absorber cavity. The upper surface of the cavity is a flat plate absorber and the lower surface is a glass window which allows solar radiation to enter the cavity. They also captured heat flow patterns in the trapezoidal cavity with a hot plate for flow visualization. The commercial software FLUENT was employed to simulate heat transfer of the cavity. The flow patterns observed in the experiments agreed fairly well with those predicted according to the computational model. An experimental and numerical study on convective heat loss occurring in a downward facing cylindrical open cavity receiver was carried out by Prakash et al. [11]. The ratio of the aperture diameter to the cavity diameter is greater than one. Nusselt number correlations were proposed for calculating convective heat loss under no-wind conditions. Paitoonsurikarn et al. [12] numerically investigated the natural convective loss from four different open cavity receiver geometries, which was validated with the experimental results as they found that the numerical and experimental results agreed well with each other. They also put forward a new correlation for natural convection based on the numerical simulation results of the three different cavities above. The correlation proposed a new concept of an ensemble cavity length scale for considering the combined effects of cavity geometry and inclination. And the correlation proposed had high accuracy compared with other correlations. Dehghan and Behnia [13] proposed a model combined with natural convection, conduction and radiation heat transfer in an open-top vertical cavity. They found that natural convection is the major mode of heat transfer and radiation has a significant effect on thermal and flow fields, forming a recirculation zone in the cavity. Baker et al. [14] introduced the CESA-1 open cavity receiver in detail in their report. The receiver controls, locations of analogic measurements, cold and warm start-ups and transient responses to cloud-induced changes were all involved. The duration of the start-up time is important for plant operation, so, in order to minimize the start-up time, appropriate operating strategies were implemented and followed during CESA-1 receiver start-up. Fang et al. [15] put forward a combined method for calculating the thermal performance of a solar open cavity receiver under windy conditions. This method coupled the Monte Carlo method, the correlations of flow boiling heat transfer and the calculation of the air flow field. They found that the air velocity reaches the maximum value when the wind comes from the side of the receiver and the thermal loss also reaches a highest value under the side-on wind. The previous studies have some shortcomings. Firstly, most of the computational studies just focused on the convective and radiative heat transfer in a simple cavity without considering the influence on the layout of absorber tubes. Secondly, the boundary conditions were all set to very simple ones, and the wall temperature or heat flux was considered to be uniform. However, most receivers such as water/steam receivers or molten salt receivers must contain absorber tubes for the heat transfer fluid that is receiving and transporting energy. The temperature and heat flux distributions are usually very non-uniform and determined by the solar irradiation conditions in the aperture. Besides, the solar cavity receiver must start-up and shut down frequently because of the non-continuity of sunlight, so the study on parameter variations during start-up of the cavity receiver is significant. 
In this work an experimental platform was designed and built for testing the thermal performance of a water/steam cavity receiver with absorber tubes. The rising curves of temperature, system pressure, mass flow and heating power during start-up processes under different operating pressures were obtained, and the start-up thermal efficiency of the receiver was also calculated. Due to the low mass flow rate, the thermal efficiency appears too low during the steady operation. Based on the computational model proposed by Fang et al. [15], a new computational model was established for studying the relationship between the thermal efficiency and the mass flow rate. The receiver of the experiment platform was then numerically studied and the curve of the thermal efficiency with the mass flow rate was obtained. An appropriate mass flow rate was finally determined for the receiver to ensure its efficient operation.

\section{Experimental Investigation on a Water/Steam Cavity Receiver}

\subsection{Experiment Platform Design and Build}

The system diagram of the experiment platform is shown in Figure 1. The water at room temperature is pumped out of the water tank by a plunger pump and fed into No. 1 preheater. The water is preheated to the temperature about $105^{\circ} \mathrm{C}$ and then flows into the deaerator.

Figure 1. System diagram of the experiment platform.

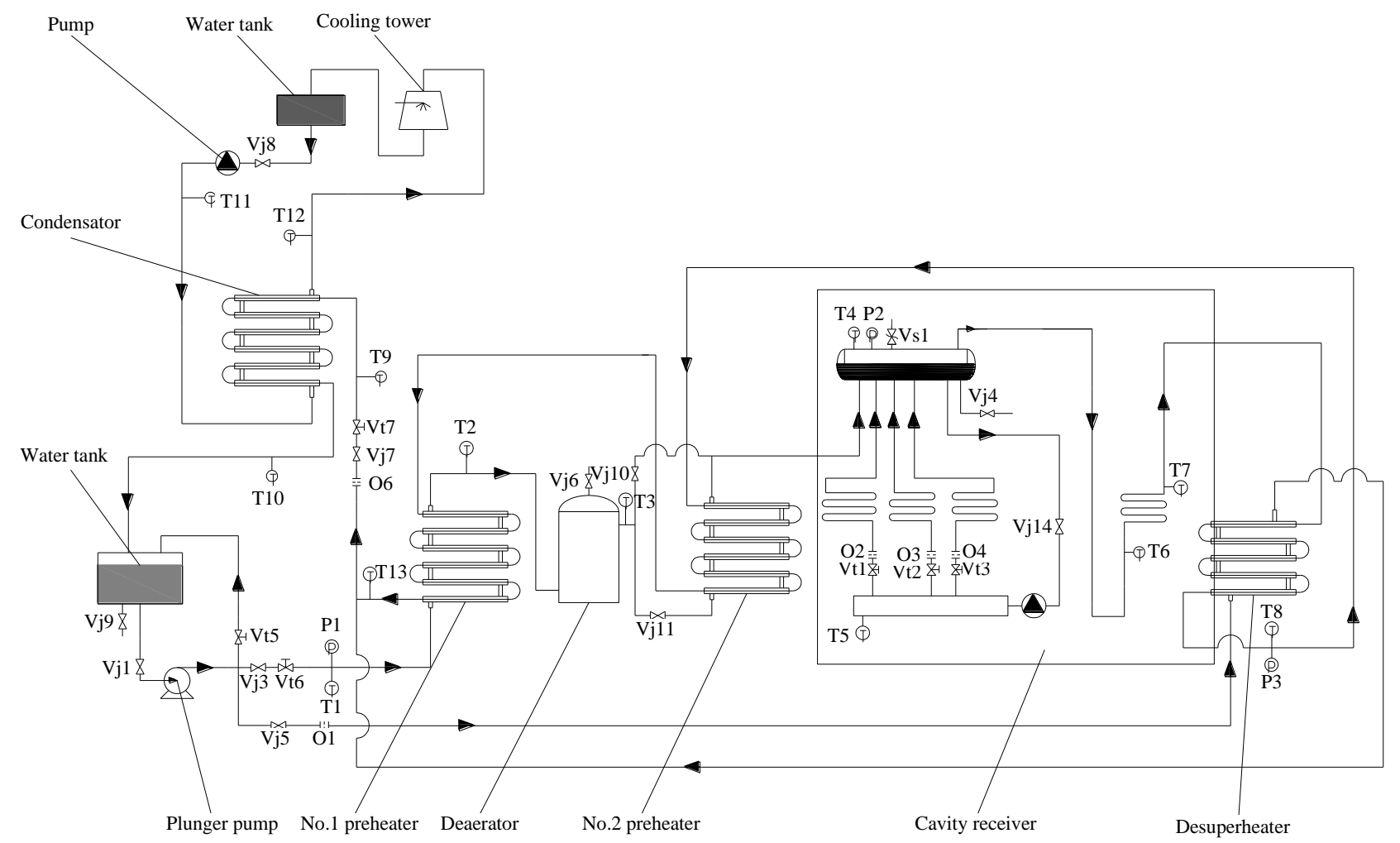

After being deaerated, the water is fed into No. 2 preheater to be further heated to a higher temperature. Then the water flows into the cavity receiver, which is the major experimental testing section. In the receiver, the water is heated into saturated water and steam by the boiling tubes and then flows into the drum for steam-water separation. The forced circulation mode is employed. After 
separation, the saturated steam outflows from the drum and is heated to a temperature above the target temperature in a superheater. Finally, the superheated steam out from the receiver flows into the desuperheater to adjust its temperature to the target state. The role played by the desuperheater is to ensure the constant outlet temperature of the superheated steam. Since the thermal performance of cavity receiver is our research object, the experiment platform has not been provided with generating equipments such as steam turbines and generators. The superheated steam out from the desuperheater flows directly to the hot side of No. 2 preheater and No. 1 preheater for energy recovery. Then the steam is cooled by the cooling-recycle system and condenses into cold water and finally goes back to the water tank. The operating temperature range of the experiment platform is from $150{ }^{\circ} \mathrm{C}$ to $400{ }^{\circ} \mathrm{C}$. The operating pressure range is $0.1 \mathrm{MPa}-5 \mathrm{MPa}$ and the mass flow rate range is $50 \mathrm{~kg} / \mathrm{h}-100 \mathrm{~kg} / \mathrm{h}$.

The cavity receiver shown in Figure $2 \mathrm{a}$ is the key component and the major experimental testing section in this experiment platform. It is a left-right symmetrical hexagonal prism with an inclined top face. The back wall is $1.95 \mathrm{~m}$ high and $1.03 \mathrm{~m}$ wide. The width of the two side walls adjacent to the back wall is $1.04 \mathrm{~m}$, while the other two side walls are $0.67 \mathrm{~m}$ in width. All walls inside the cavity are covered with heat-insulating material to reduce heat loss. There is an aperture, with a size of $1.2 \mathrm{~m} \times 0.8 \mathrm{~m}$, on the front surface of the cavity, and a door also covered with insulating material is installed covering on the aperture. After finishing the experiment the door is tightly closed on the aperture to seal the cavity for keeping it warm inside.

Figure 2. (a) Cavity geometry; (b) Absorber tubes layout. (1-Boiling tubes 2-Superheated tubes).

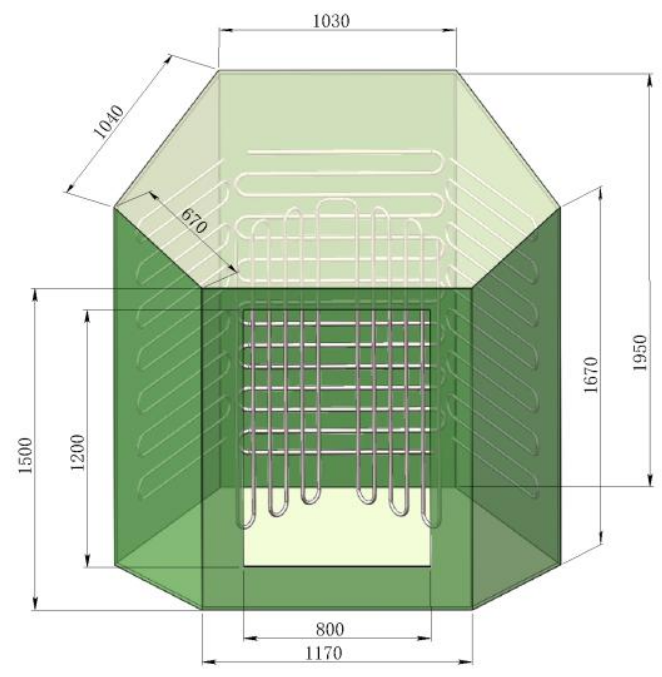

(a)

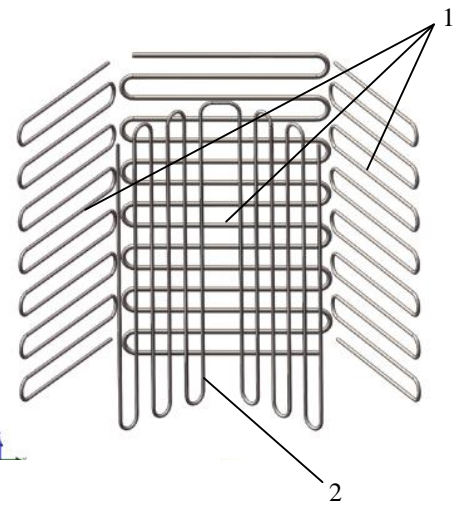

(b)

Figure $2 \mathrm{~b}$ shows the layout of boiling tubes and superheated tubes. The geometry of the receiver is very similar to that of CESA-1 receiver in Spain. According to Baker's [14] description referring to CESA-1, the higher heat flux will mainly appear on three back walls, so boiling tubes are laid out on these walls and superheated tubes are installed in the center of the receiver. Since the electrical heating energy is given to the absorber tubes in the experiment platform and there is no incident solar flux in the aperture, very loosely packed tubes can be laid inside the cavity. In a real solar cavity receiver, this kind of layout will cause severe heat loss because most of the back surfaces are exposed to the incident solar radiation. The central boiling tubes have 15 passes, and the outer diameter of every tube is 
$20 \mathrm{~mm}$, including the $3 \mathrm{~mm}$ thickness of the stainless steel wall, while the side boiling tubes and superheated tubes have outer diameters of $14 \mathrm{~mm}$ including the $2 \mathrm{~mm}$ thickness of the stainless steel walls. The side boiling tubes and superheated tubes have 14 passes and 12 passes respectively. Figure 3 shows a schematic graph of the receiver. There is a drum above the receiver for steam-water separation. The volume of the drum is $0.5 \mathrm{~m}^{3}$ and the weight is $750 \mathrm{~kg}$.

Figure 3. Cavity receiver. (1-drum 2-door 3-boiling tubes 4-superheated tubes).
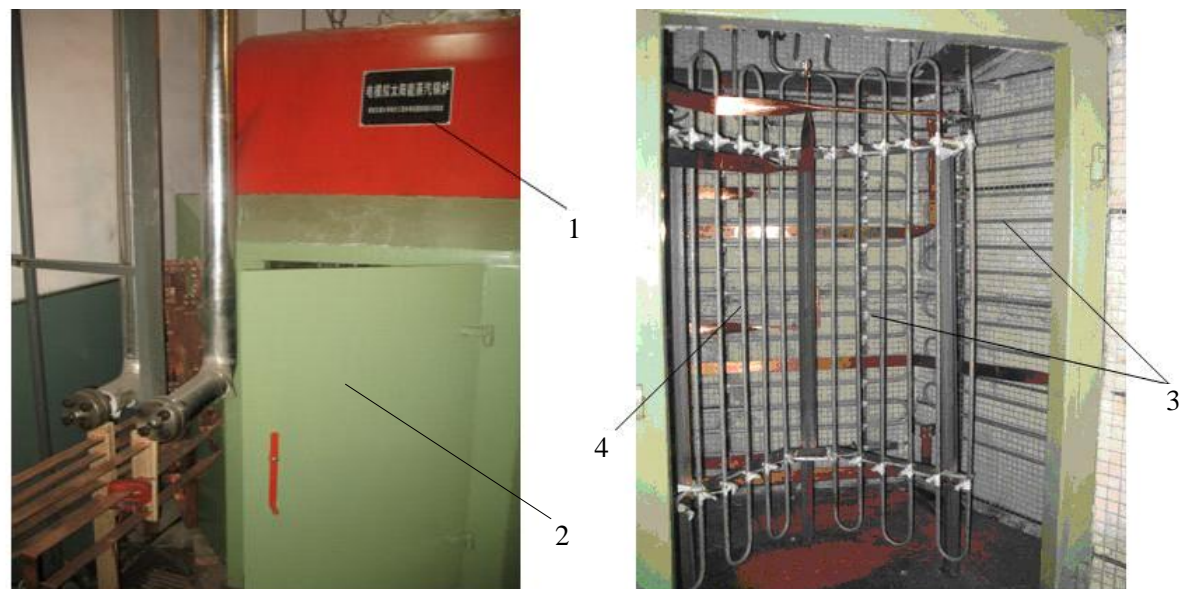

The electrical heating mode was chosen to supply energy for the absorber tubes. It can provide high heat flux and convenient power control. On the basis of Baker [14] and Fang's [15] results, about 48\% of the net energy is absorbed by the central boiling panel and $26 \%$ by each side one. This net energy ignores the radiative and convective heat loss, and is the only energy transferred from the tubes to the fluid. Hence, in order to simulate the same conditions, the electrical heating power for the central boiling panel is twice as high as that for each side one in the present study. According to this heating power distribution, the mass flow rate distribution of three boiling panels was designed as $300 \mathrm{~kg} / \mathrm{h}$ for the central panel and $150 \mathrm{~kg} / \mathrm{h}$ for each side one. This kind of design can ensure that the boiling tubes have approximately the same outlet quality. It should be noticed that these mass flow rates are the recirculating flow rates. It means only part of the liquid is heated into steam and the majority is recirculated in the boiling tubes. The steam-water circulation ratio is about 6-10 under steady operating conditions. In Fang's [15] research, the distribution of surface heat flux on the boiling tubes appears as non-uniform. The middle part of each boiling panel gets a greater heat flux and the greatest value appears in the middle part of the central boiling panel. There are two reasons for this distribution of the surface heat flux. One is that the solar energy concentrated in the aperture is highly non-uniform. The other is that the receiver geometry is usually in an irregular shape. In order to simulate this non-uniform heat flux distribution, one absorber tube is divided into several sections, which are heated separately. The electrical heating way for one of heating sections of the absorber tubes is shown in Figure 4. The middle of the heating section is connected to one pole of the power supply. The two ends of the heating section are both connected to the other pole. By this electrical heating method the electrical insulation between the heating section and other connected parts can be guaranteed. The other sections of this tube are also heated in the same way, so the ends of the tubes are also heated, although this is not shown in Figure 4. The heating is simply being done by resistance in the tubes themselves. 
Figure 4. Electrical heating way for every heating section.

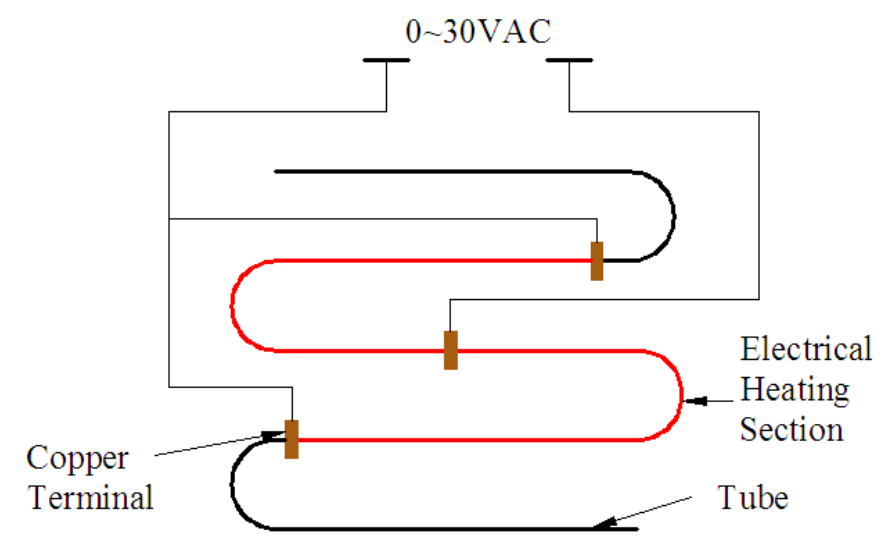

The experimental platform aims to test the thermal performance of the water/steam cavity receiver during start-up processes. The temperature rise rate is considered as a main control variable. Since there are no authoritative criteria for the temperature rise rate of the cavity receiver, the start-up criteria for boilers are referenced. According to the textbook Principles of Boilers written by Fan [16], the average temperature rise rate of the drum as recommended shall not exceed $1.5{ }^{\circ} \mathrm{C} / \mathrm{min}$, while the average temperature rise rate of the superheated steam shall be less than $2.0{ }^{\circ} \mathrm{C} / \mathrm{min}$ during start-up processes. The steam mass flow rate is an auxiliary control variable, which increases linearly with the start-up time determined by the temperature rise rate. Other variables, including the variables representing the pressure in the drum and the heating power, are both dependent variables. They are determined by the temperature rise rate and the steam flow rate.

For calculating the thermal efficiency of receiver, the temperature and mass flow rate of the feedwater and steam at the inlet and outlet, the drum pressure and temperature, and the electrical heating power must be measured, so a data acquisition system is allocated for the measurement of temperature, pressure, mass flow rate and heating power at the key positions of the experimental system. The thermal efficiency of the receiver, $\eta$, is defined as the ratio of the energy absorbed by the receiver, $Q_{r}$, to the total electrical heating power $Q_{h}$ :

$$
\eta=\frac{Q_{r}}{Q_{h}}
$$

The energy absorbed by the receiver, $Q_{r}$, can be described as follows:

$$
Q_{r}=\dot{m}_{o} \times h_{o}-\dot{m}_{i} \times h_{i}+c_{w} m_{w} \times \frac{d T}{d t}
$$

where $\dot{m}$ and $h$ represent the mass flow rate and the enthalpy respectively. The subscripts $i, o$ and $w$ represent the inlet of receiver, the outlet of receiver and water (in the receiver), respectively. The first two terms on the right of Equation (2) represent the energy taken away by fluid flowing in and out of the receiver, including the energy brought by the feedwater and the energy taken away by the superheated steam. In order to maintain the liquid level in the drum at a constant height, the mass flow rate of the inlet should be equal to that of the outlet. The third term represents the energy absorbed by water in the receiver due to temperature rising during start-up processes. The total electrical heating power $Q_{h}$ can be expressed as follows: 


$$
Q_{h}=\sum_{i=1}^{n} V_{i} I_{i}
$$

where $V$ and $I$ respectively represent the voltage and current of each heating section, and $n$ represents the number of the heating sections. In the experiments, a low lever AC voltage is applied for the absorber tubes. A couple of current transformers are installed to collect the current measured by AC ammeters. The electric potential difference is measured using AC voltmeters. The current transformers, ammeters and voltmeters all have the measurement errors of $\pm 0.5 \%$ and high stability.

\subsection{Experimental Results and Discussion}

A couple of experiments were conducted to study the thermal performance of the receiver during start-up processes under different target pressures. Figure 5 shows five start-up curves under the target pressure of 2.6 $\mathrm{MPa}$.

Figure 5. Start-up curves under operating pressure $p=2.6 \mathrm{MPa}$.

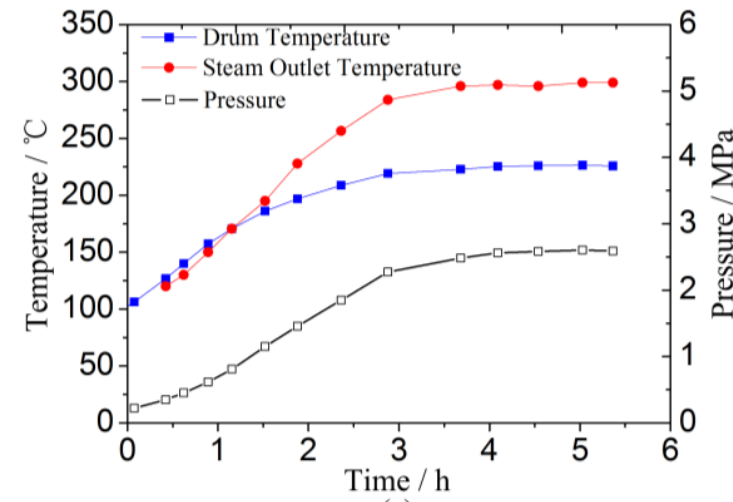

(a)

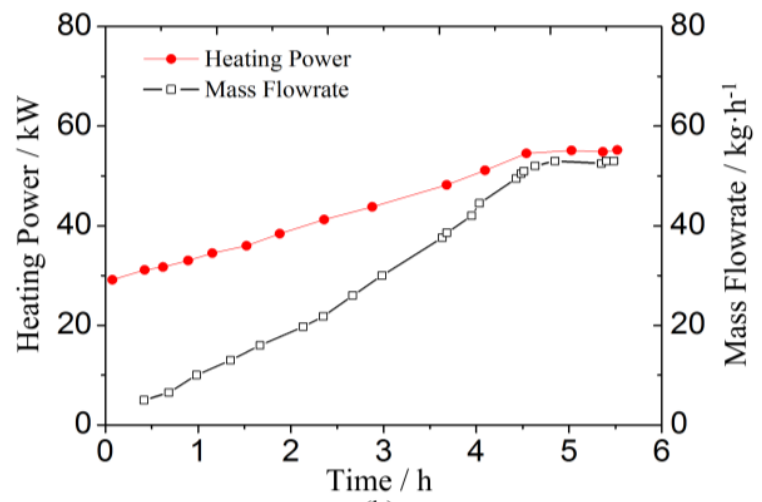

(b)

The start-up curves of 4.2 MPa and 5.1 MPa are shown in Figures 6 and 7.

Figure 6. Start-up curves under operating pressure $p=4.2 \mathrm{MPa}$.

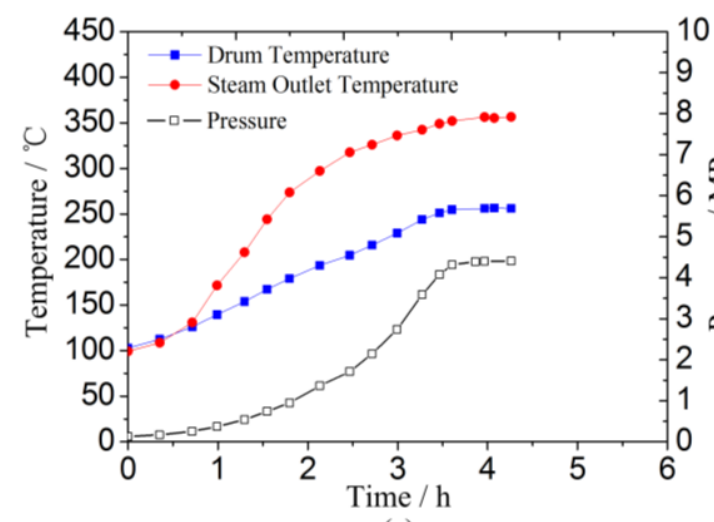

(a)

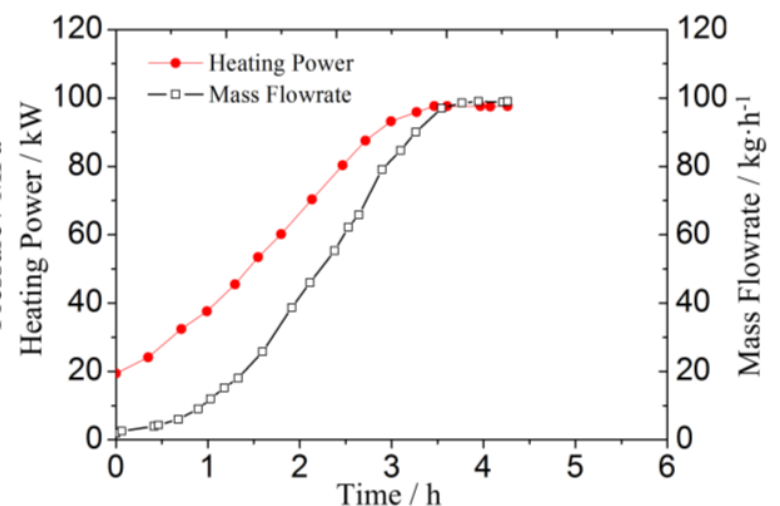

(b) 
Figure 7. Start-up curves under operating pressure $p=5.1 \mathrm{MPa}$.

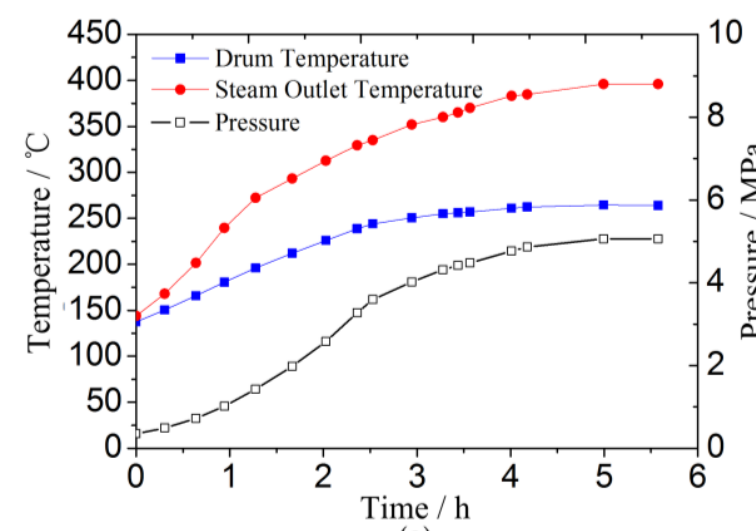

(a)

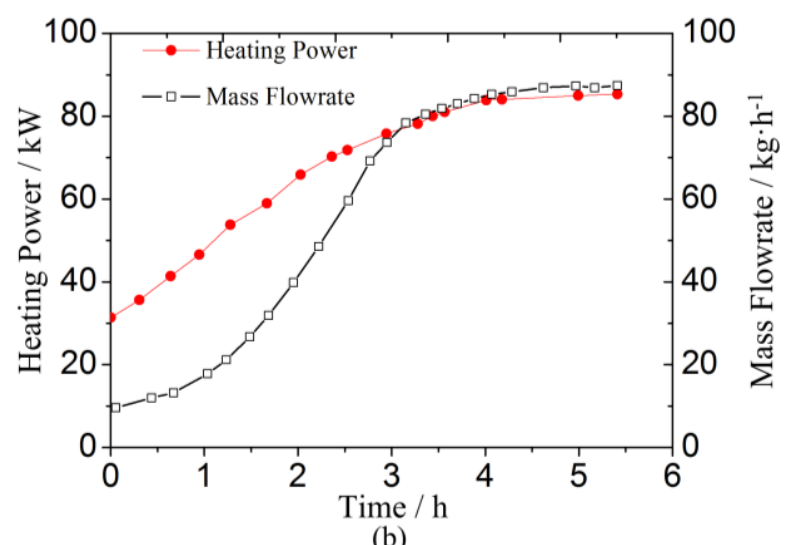

(b)

The five start-up curves represent drum temperature, steam temperature, pressure, heating power and mass flow rate rising with the start-up time. Among the five curves, the drum temperature rise rate and the steam temperature rise rate are control variables. The maximum temperature rise rate is listed in Table 1.

Table 1. Maximum rising rate of the control variables during start-up process.

\begin{tabular}{cccc}
\hline Pressure/MPa & $\begin{array}{c}\text { Drum temperature } \\
\text { rising rate } /{ }^{\mathbf{C}} \mathbf{C} \cdot \mathbf{m i n}\end{array}$ & $\begin{array}{c}\text { Steam temperature } \\
\text { rising rate } /{ }^{\circ} \mathbf{C} \cdot \mathbf{m i n}\end{array}$ & $\begin{array}{c}\text { Steam flow rising } \\
\mathbf{r a t e} / \mathbf{k g} \cdot \mathbf{h}^{\mathbf{2}}\end{array}$ \\
\hline 2.6 & 0.99 & 1.21 & 11.52 \\
4.2 & 0.77 & 1.77 & 37.24 \\
5.1 & 0.72 & 1.79 & 30.58 \\
\hline
\end{tabular}

The steam flow rate increases linearly with the start-up time and the rate is an auxiliary control variable. Since experimental variables are usually hard to control, the steam flow rate increases much more slowly both at the beginning and at the end of start-up in the experiments. Therefore, the flow rate in Figures 5-7 only linearly increases from some time after the start of start-up to some time before the end of start-up. It takes $4.6 \mathrm{~h}, 3.5 \mathrm{~h}$ and $5.0 \mathrm{~h}$, respectively, to finish the whole start-up process under three different target pressures. Then the drum pressure and temperature, steam outlet temperature, heating power and mass flow rate are stable. For the sake of safety, the values of temperature and mass flow rise rate used as control variables are selected very conservatively in the experiments, so the start-up time is a little longer than that of a real solar cavity receiver which usually takes 1-2 hours to finish the start-up process. If higher temperature and mass flow rising rate are selected, the start-up time of our cavity receiver would be minimized.

The thermal efficiency of the receiver during start-up can be calculated by using the method introduced in Section 2.1 and shown in Figure 8. As can be seen in Figure 8, the overall thermal efficiency of the receiver is rather low. The thermal efficiency is only about $56 \%$, even in steady operation under the pressure condition of 2.6 MPa. The thermal efficiencies of 4.2 MPa and 5.1 MPa appear slightly higher, but still very low, and are only about $68 \%$ and $70 \%$ after start-up. As was mentioned, the geometry of the receiver is very similar to that of CESA-1 receiver in Spain, but the former has much lower thermal efficiency. In Baker's [14] report, the thermal efficiency of CESA-1 receiver can reach about $90 \%$ during steady operation, which is shown in Figure 9. The low thermal 
efficiency is attributed to the mismatching of the receiver geometry and the steam mass flow rate. In the present study, the mass flow rate is only $50 \mathrm{~kg} / \mathrm{h}-100 \mathrm{~kg} / \mathrm{h}$ when the operating pressure and temperature are stable. Due to the low mass flow rate, the corresponding energy absorbed by the receiver is also low, thereby the heat loss represents quite a high proportion of the total energy. Because the maximum mass flow rate of the experiment platform is $100 \mathrm{~kg} / \mathrm{h}$, the thermal efficiency of the receiver with the mass flow rate more than $100 \mathrm{~kg} / \mathrm{h}$ cannot be studied experimentally.

Figure 8. Thermal efficiency of receiver during start-up process.

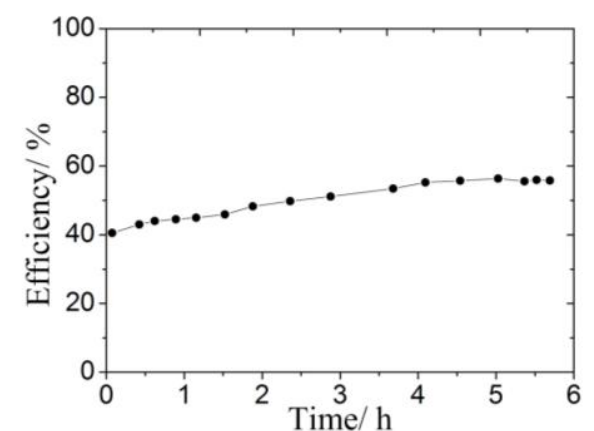

(a) 2.6 MPa

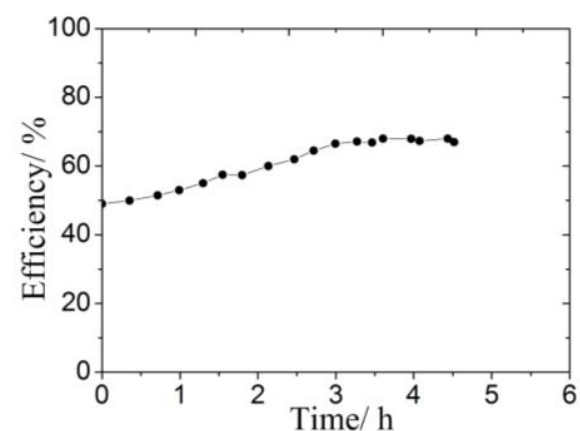

(b) $4.2 \mathrm{MPa}$

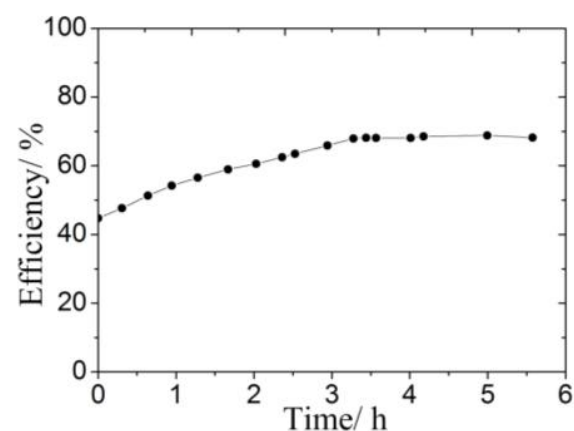

(c) $5.1 \mathrm{MPa}$

Figure 9. Thermal efficiency of CESA-1.

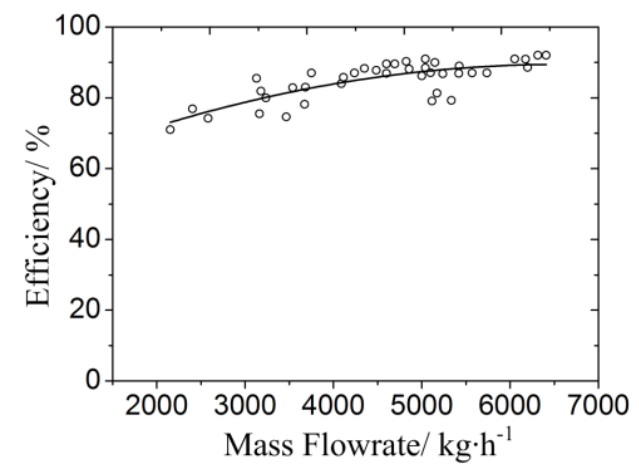

\section{Numerical Investigation on a Water/Steam Cavity Receiver}

In order to obtain a detailed relationship between the thermal efficiency and the mass flow rate, the receiver shown in Figure 2 was studied numerically. Based on the computational model proposed by Fang et al. [15] for evaluating the thermal efficiency of saturated steam cavity receiver, a new computational model with the heat transfer of superheated tubes was established. To ensure efficient operation of the cavity receiver, further studies are expected to be conducted after the validation of the computational model, to acquire the curve of thermal efficiency versus mass flow rate for determining an appropriate mass flow rate for the given receiver.

\subsection{Computational Model}

Fang et al. [15] proposed a combined method for calculating the thermal efficiency of a solar cavity receiver. This method can be divided into three aspects: the calculation of temperature and heat flux inside the receiver with the Monte Carlo method, the calculation of convective heat transfer inside the 
absorber tubes and the calculation of air flow field around the receiver. The thermal efficiency is finally obtained by coupling these three aspects with an iterative scheme.

The Monte Carlo method is used to calculate the wall temperature and the surface heat flux inside the receiver. This method for radiation is introduced in detail in the textbook by Modest [17], and its basic thought is that the radiative heat transfer process can be divided into three sub-processes: emission, reflection and absorption. Every sub-process has a probability of occurrence. The receiver is divided into many surface units. Let every unit emit a certain quantity of light rays and every light ray is tracked and judged by considering whether it is absorbed or reflected by the interface or it escapes from the receiver. Therefore, the radiative heat transfer factor $R D_{i j}$ can be computed by statistical analysis. $R D_{i j}$ is the ratio of the number of light rays that unit $j$ gains from unit $i$ to the number of light rays emitted by unit $i$. Then the temperature and heat flux of surface units can be calculated by solving the energy equations expressed as $R D_{i j}$. If the light ray escapes from the receiver through the aperture, it is considered as the radiative heat loss, so the radiative heat loss can also be obtained by using the Monte Carlo method. No incident solar flux but only the electrical heating energy was supplied to the absorber tubes in the present study, so the temperature was set to the ambient state in the aperture of the cavity receiver when calculating with the Monte Carlo method. It should be noticed that the radiative heat transfer factor $R D_{i j}$ only needs to be calculated once before iteration.

Subcooled water delivered to boiling tubes is heated into saturated state and it undergoes a phase transition. Then the saturated steam is changed into superheated steam in superheated tubes. The flow during this process is considered to fall into three regions: single-phase flow region, including supercooled liquid single-phase region and superheated steam single-phase region, subcooled boiling flow region and saturated boiling flow region. Among them the subcooled boiling flow region can be subdivided into three regions according to the mechanism of heat transfer, namely, partial boiling flow region, fully developed boiling flow region and significant void flow region. Fang et al. [15] introduced these flow regions in detail. The calculation of convective heat transfer inside the absorber tubes can be conducted by selecting appropriate heat transfer correlations and identification criteria for each flow region. The correlations recommended by Kandlikar [18,19] and the identification criteria suggested by Hsu et al. [20] were used in the calculation. As long as the inlet conditions of absorber tubes and heat flux on the surface of tubes are known, the convective heat transfer coefficient and the wall temperature of tubes can be calculated.

The existence of aperture causes indispensable radiative heat loss and natural convective heat loss of the receiver. The natural convective heat loss between the receiver and the air is gained by calculating the air flow field around the receiver. The commercial software FLUENT is chosen to calculate the natural convective heat transfer. The standard $k-\varepsilon$ turbulent model is selected and the SIMPLE algorithm is employed. Gravity term is considered in the calculation. Since the air pressure in the system varies little in the whole fluid domain, being nearly equal to $1 \mathrm{~atm}$, the physical properties of air is set to vary only with temperature. The piecewise-linear function is employed for calculating the density, specific heat, thermal conductivity and viscosity. The walls of the receiver are considered adiabatic and no-slip velocity boundary conditions are adopted. The boundary layer elements are also created. There are six rows of boundary layer elements in the present work. The height of the first row is $1 / 5$ of the length of the grid on the boundary and the increasing ratio between every two rows is 1.3. The speed of far field is set to 0. If the conditions of air flow in the far field and the wall temperature 
of cavity and absorber tubes are known, the natural convective heat loss between the receiver and the air can be calculated. In the present model, when the number of cells increases to $1,250,307$, the result indicates that the mesh converges.

The parameters required for calculating the three aspects introduced above are interrelated and none of these aspects can be solved alone. When calculating the wall temperature of cavity and the heat flux on the surface of absorber tubes with the Monte Carlo method, the wall temperature of absorber tubes and the natural convective heat loss must be known. When calculating the wall temperature of absorber tubes by selecting appropriate heat transfer correlations, the heat flux on the surface of absorber tubes must be used. Besides, when calculating the natural convective heat loss of the receiver with FLUENT, the wall temperature of cavity and absorber tubes must be known. So an iterative scheme is needed by coupling these three aspects.

The calculation method raised by Fang et al. [15] can be used to calculate the net energy that the solar cavity receiver gains and other thermal performance parameters under the condition of providing the boundary heat source (i.e., solar energy distribution in the aperture). It is contrary in the present work, that boundary heat source (i.e., electrical heating energy delivered to the absorber tubes) is calculated by giving the net energy required by the receiver. Therefore, some adjustment is made for the model to adapt to the present calculation. Before iterative calculation, the radiative heat transfer factor $R D_{i j}$ and the net energy required by the receiver must be calculated first.

For the water/steam cavity receiver of the experiment platform, the electrical heating energy is partly dissipated due to convective and radiative heat loss and the rest is absorbed by tubes to heat the subcooled water into superheated steam. This rest part of energy is the net energy required by the receiver. The subcooled water is heated into saturated liquid and steam in boiling tubes. $h_{1}$ and $h_{2}$ represent the specific enthalpy of the saturated liquid and steam. $\dot{m}_{1}$ and $\dot{m}_{2}$ respectively represent the outlet saturated liquid mass flow rate and the saturated steam mass flow rate. It should be noticed here that only part of liquid is heated into steam and most is recirculated in the boiling tubes. Equation (4) expresses the energy required by the boiling tubes:

$$
Q_{b o}=\left(\dot{m}_{1} \times h_{1}+\dot{m}_{2} \times h_{2}\right)-\left(\dot{m}_{1}+\dot{m}_{2}\right) \times h_{i}
$$

where $h_{i}$ represents the inlet specific enthalpy of subcooled water.

The saturated steam which mass flow rate is $\dot{m}_{2}$ outflows from the drum and is heated into superheated steam in superheated tubes. $h_{\text {sup }}$ and $h_{2}$ are respectively the specific enthalpy of outlet superheated steam and inlet saturated steam. The energy required by superheated tubes can be described as follows:

$$
Q_{\text {sup }}=\dot{m}_{2} \times\left(h_{\text {sup }}-h_{2}\right)
$$

Thus, the net energy required by the receiver is the sum of $Q_{b o}$ and $Q_{s u p}$ :

$$
Q_{n e t}=Q_{b o}+Q_{\text {sup }}
$$

Figure 10 shows the flow chart for calculating the thermal performance of the cavity receiver. The calculation steps shown on the right side of the figure were put forward by Fang et al. [15]. It consists of two loops: the convective heat loss is calculated in the outer loop, and the wall temperature and the heat flux are calculated by coupling the Monte Carlo method and the heat transfer inside the tubes in 
the inner loop. Because the electrical heating energy can hardly be calculated directly by giving the net energy required by the receiver, a new iterative loop which nests the two former ones is added as shown on the left side of Figure 10. The value of heating energy is assumed in the calculation at first, and then the net energy gained by the receiver can be obtained by adopting the calculation steps on the right side of Figure 10. According to the comparison between the net energy that the receiver gains and the one that the receiver requires, the heating energy fed to the absorber tubes will be properly adjusted for recalculating the net energy gained by the receiver. The details of the whole calculation process are described as follows:

1. The radiative heat transfer factor $R D_{i j}$, the net energy $Q_{b o}$ and $Q_{s u p}$ required by boiling tubes and superheated tubes are calculated first. They are not involved in the iteration loops.

2. Assume an initial electrical heating power $Q_{h}$ of absorber tubes. As it is similar to the experimental condition, a half of electrical heating power is provided for central boiling tubes and a quarter is for each side one.

3. According to the proportion distribution of heating power in the experiment, the electrical heating power for each surface unit of absorber tubes is calculated.

4. Set an initial convective heat loss $Q_{c, \text { loss }}$ for each surface unit of the receiver.

5. Assume an initial wall temperature $T_{t}$ for each surface unit of absorber tubes.

6. Take the convective heat loss of the receiver, the heating power and the wall temperature of absorber tubes as the boundary conditions. Use the Monte Carlo method to calculate the wall temperature of the cavity, the radiative heat loss of the receiver and the heat flux $q_{t}$ of every surface unit on the tubes transferred into working fluid inside. In this step, the radiative heat transfer factor $R D_{i j}$ is used.

7. Based on the correlations of flow heat transfer, the inlet conditions of absorber tubes and the heat flux on the surface of tubes calculated by Step (6), a new wall temperature $T_{t}$ of tubes is gained.

8. Compare $T_{t}$ with $T_{t}^{\prime}$. If the difference between these two values is larger than a given allowable error $\varepsilon$, then go to Step (6) and replace the value $T_{t}$ with $T_{t}^{\prime}$ before repeating the calculation. The process above shall be repeated till the difference between $T_{t}$ and $T_{t}^{\prime}$ is smaller than $\varepsilon$. The wall temperature of the cavity and tubes, the radiative heat loss of the receiver and the heat flux of the tubes will converge in the condition that the convective heat loss and electrical heating power are assumed.

9. After the wall temperature of the cavity and tubes converge, the calculation of air flow field around the cavity can be conducted to gain a new convective heat loss $Q_{c, l o s s}^{\prime}$.

10. Compare $Q_{c, \text { loss }}$ with $Q_{c, \text { loss }}^{\prime}$. If the difference between the two values is larger than a given allowable error $\varphi$, then replace the value $Q_{c, \text { loss }}$ with $Q_{c, \text { loss }}^{\prime}$ and go to Step (5) to recalculate the convective heat loss of the receiver. Keep iterating till the difference between $Q_{c \text {,loss }}$ and $Q_{c, l o s s}^{\prime}$ is smaller than $\varphi$.

11. After the convergence of convective heat loss, the wall temperature of the cavity and tubes, the radiative heat loss of the receiver and the heat flux of the tubes are calculated in the condition that the heating power is assumed. So the energy gained by boiling tubes $Q_{b o}^{\prime}$ and superheated tubes $Q_{\text {sup }}^{\prime}$ can be obtained from the following expression. 


$$
Q_{b o(\sup )}^{\prime}=\sum q_{t} S_{t}
$$

where $S_{t}$ represents the area of surface unit on absorber tubes.

12. Compare $Q_{b o}$ with $Q_{b o}^{\prime}$ and $Q_{s u p}$ with $Q_{s u p}^{\prime}$. If the difference is larger than a given allowable error $\varphi$, then adjust heating power $Q_{h}$ and go to Step (3) to recalculate. Do iteration until the difference is smaller than $\varphi$. The real heating power will be gained finally.

13. When the electrical heating power converges, the whole calculation is finished. The net energy that the receiver requires can be provided by the heating power at present. The thermal efficiency of receiver $\eta$ can be calculated by Equation (8).

$$
\eta=\frac{\sum q_{t} S_{t}}{Q_{h}}
$$

Figure 10. Flow chart for calculating the thermal performance of cavity receiver.

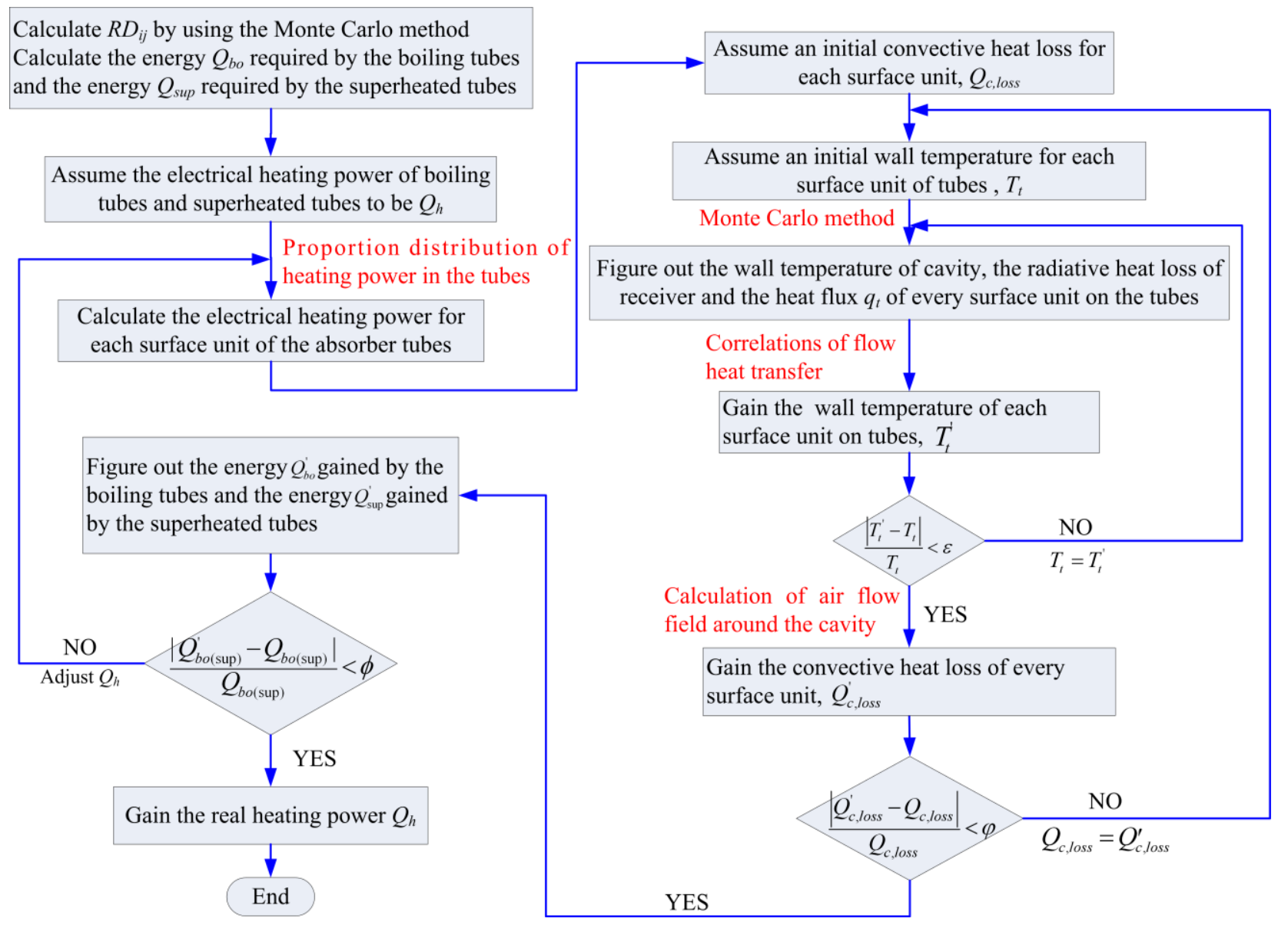

The calculation of radiative heat transfer factor takes quite a long time, since the radiative heat transfer takes place between any two units. When the Monte Carlo method is employed to calculate $R D_{i j}$, the number of light rays emitted by every unit is very important. A proper number of light rays can ensure the accuracy of results and the least time of calculation. Another time-consuming task is the calculation of convective heat transfer. If the initial temperature is set to be the ambient temperature and the initial velocity is set to be zero, it will need thousands of iterations to obtain the converged results. The wall temperature and the heat flux are calculated by solving the radiation energy 
equations. Because the coefficient matrix of equations is a strictly diagonally dominant matrix, it can meet the convergence condition of Gauss-Seidel iteration. The calculation of air flow field around the cavity employs the second order upwind scheme, which is absolutely convergent.

\subsection{Numerical Results and Discussion}

The thermal performance of the water/steam cavity receiver shown in Figure 2 during steady operation was studied numerically in the present study. To verify the reliability of the computational model, the thermal performances of the receiver under three experimental conditions introduced in Section 2 were simulated. The mass flow rate is independent of the pressure in every experimental condition. The comparison of experimental and numerical results is shown in Figure 11 and Table 2. A good agreement can be found between the experimental data and the numerical data, especially when the operating pressure is high. Since the heat insulation parts of the experiment platform were treated well and the measurement was accurate, the experimental results are significant and can be used as reference values for the numerical studies. It is reasonable that the thermal efficiency errors between the numerical and experimental results reach 5.9\%-11.1\%. The good agreement demonstrates a high reliability of the computation model.

Figure 11. Comparison of experimental and numerical results.

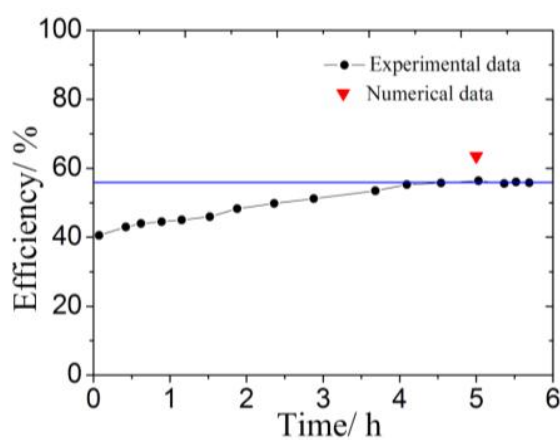

(a) $2.6 \mathrm{MPa}$

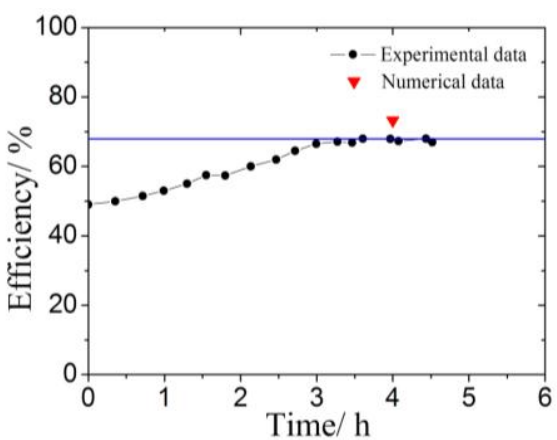

(b) $4.2 \mathrm{MPa}$

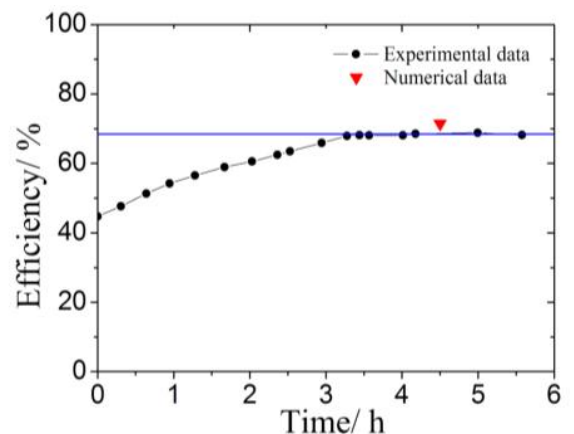

(c) $5.1 \mathrm{MPa}$

Table 2. Comparison of experimental and numerical results.

\begin{tabular}{ccccc}
\hline Pressure/MPa & $\begin{array}{c}\text { Mass flow rate, } \\
\mathbf{k g} / \mathbf{h}\end{array}$ & $\begin{array}{c}\text { Experimental } \\
\text { efficiency/\% }\end{array}$ & $\begin{array}{c}\text { Numerical } \\
\text { efficiency/\% }\end{array}$ & Error/\% \\
\hline 2.6 & 53 & 56.4 & 63.5 & 11.1 \\
4.2 & 99 & 68.0 & 73.3 & 7.2 \\
5.1 & 86 & 67.3 & 71.5 & 5.9 \\
\hline
\end{tabular}

After verifying the reliability of the computational model, the relationship between thermal efficiency and mass flow rate was studied. Under the pressure of 5.1 MPa and at the steam temperature of $400{ }^{\circ} \mathrm{C}$, the curve of thermal efficiency versus mass flow rate was obtained, as shown in Figure 12. The mass flow rate varies from $53 \mathrm{~kg} / \mathrm{h}$ to $250 \mathrm{~kg} / \mathrm{h}$ and the inverted triangle in Figure 12 represents the experimental point. As can be found in Figure 12, the result indicates that the thermal efficiency increases when the mass flow rate changes from $53 \mathrm{~kg} / \mathrm{h}$ to $250 \mathrm{~kg} / \mathrm{h}$. It increases more remarkably when the mass flow rate is low. When the mass flow rate is less than $100 \mathrm{~kg} / \mathrm{h}$, the thermal efficiency 
is lower than $75 \%$, while the large mass flow rate which is more than $200 \mathrm{~kg} / \mathrm{h}$ can cause a high thermal efficiency over $85 \%$. The natural convective heat loss is about four times more than the radiative heat loss. It is the main component of heat loss which can also be observed from Figure 12.

Figure 12. Curve of thermal efficiency with mass flow rate.

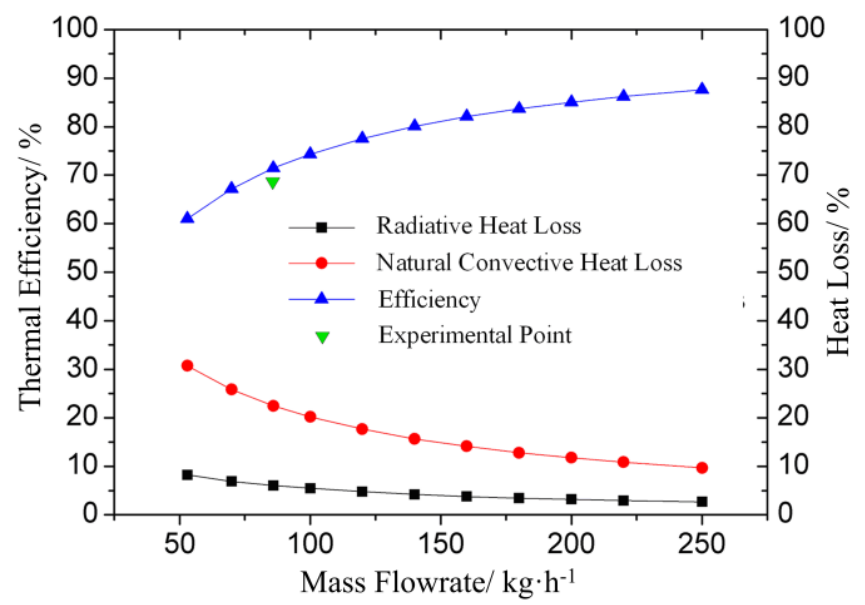

The reason for the thermal efficiency increase with mass flow rate may be explained as below. The change of mass flow rate does not affect much the temperature of absorber tubes when the mass flow rate varies from $53 \mathrm{~kg} / \mathrm{h}$ to $250 \mathrm{~kg} / \mathrm{h}$, so the absolute value of heat loss of the receiver also shows no obvious increase. On the other hand, the increasing mass flow rate can lead to a relatively large increase of the net energy gained by the receiver, so the thermal efficiency of the receiver increases accordingly. Figure 13 is the distribution of the outer wall temperature of absorber tubes when the mass flow rate is respectively $53 \mathrm{~kg} / \mathrm{h}$ and $250 \mathrm{~kg} / \mathrm{h}$. As can be seen in Figure 13, the outer wall temperature of the tubes only increases by $8{ }^{\circ} \mathrm{C}$ although the mass flow rate increases by about five-fold.

Figure 13. Distribution of the outer wall temperature of absorber tubes.

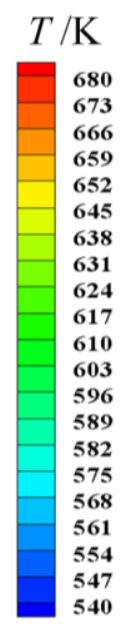

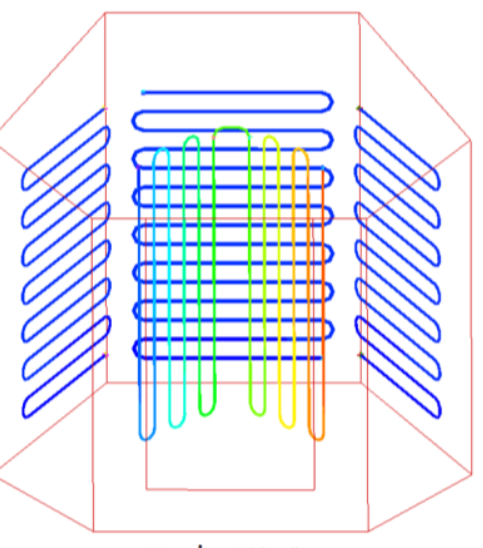

(a) $\dot{m}=53 \mathrm{~kg} / \mathrm{h}$

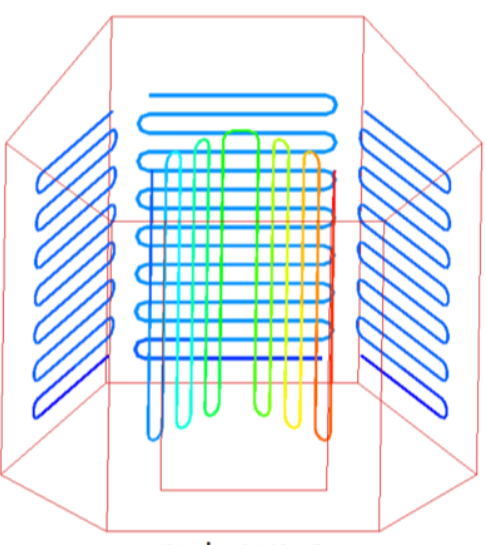

(b) $\dot{m}=250 \mathrm{~kg} / \mathrm{h}$

Figures 14 and 15 illustrate the air temperature field and the air velocity field around the receiver on the central vertical section, respectively. The air temperature gradually increases from the bottom to the top inside the receiver. The low temperature air flows into the receiver from the bottom aperture and then is heated by the walls and absorber tubes. As the density becomes lower, the heated air flows 
out of the receiver from the top aperture. This air motion generates the natural convective circulation inside the cavity. The air temperature increases apparently by about $70{ }^{\circ} \mathrm{C}$ from bottom to top, and the average velocity is about $0.6 \mathrm{~m} / \mathrm{s}$. In Figures 14 and 15 , when the mass flow rate varies from $53 \mathrm{~kg} / \mathrm{h}$ to $250 \mathrm{~kg} / \mathrm{h}$, the air temperature and the velocity field around the receiver are barely changed.

Figure 14. Air temperature field in the central vertical section of the receiver.

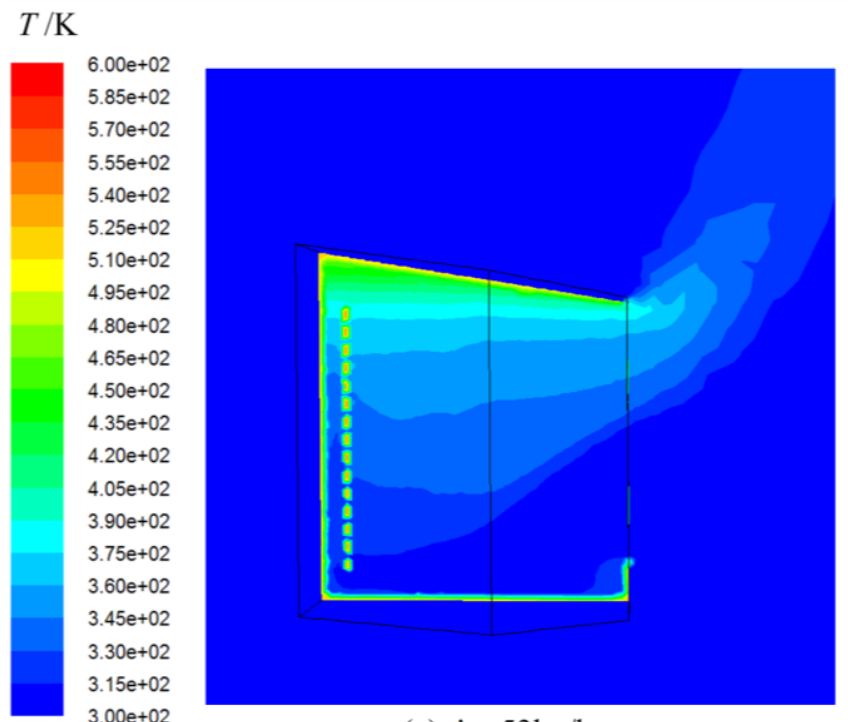

(a) $\dot{m}=53 \mathrm{~kg} / \mathrm{h}$

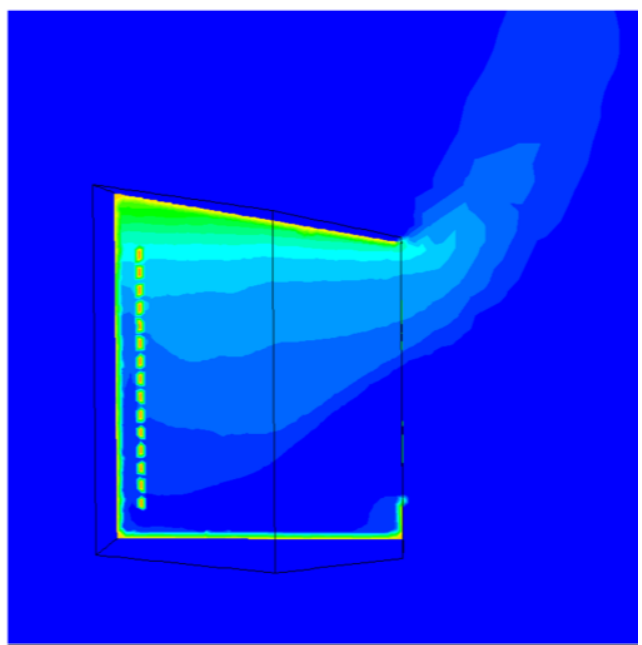

(b) $\dot{m}=250 \mathrm{~kg} / \mathrm{h}$

Figure 15. Air velocity field in the central vertical section of the receiver.

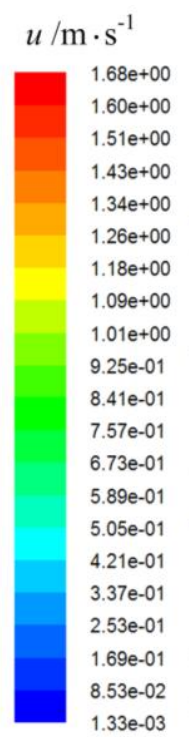

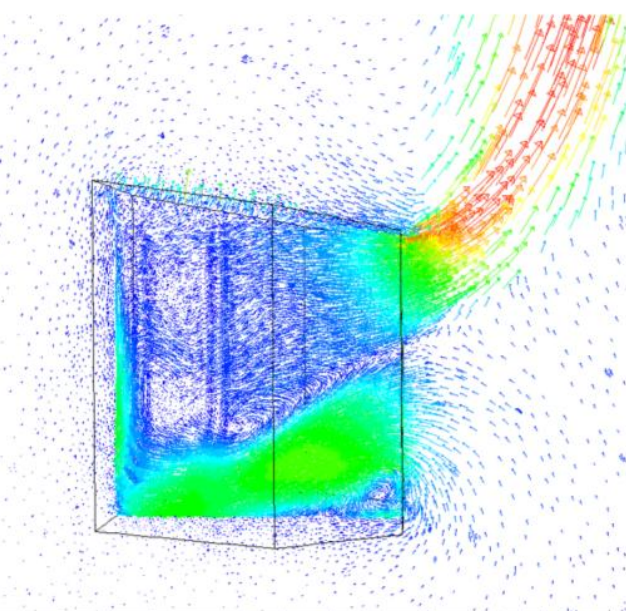

(a) $\dot{m}=53 \mathrm{~kg} / \mathrm{h}$

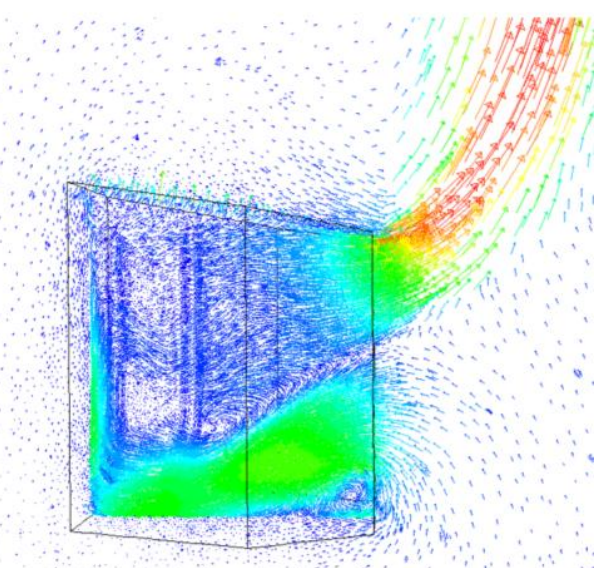

(b) $\dot{m}=250 \mathrm{~kg} / \mathrm{h}$

Although the thermal efficiency of the receiver increases when the mass flow rate varies from $53 \mathrm{~kg} / \mathrm{h}$ to $250 \mathrm{~kg} / \mathrm{h}$, it certainly cannot increase without limit. The higher the mass flow rate is, the higher the wall temperature that can be obtained. Although the increasing mass flow rate can also lead to the increase of net energy gained by the receiver, the heat loss will increase more rapidly than the net energy with further increase of mass flow rate, especially the radiative heat loss because it is in direct proportion to the wall temperature to the fourth power. Since the mass flow rate of the experiment platform is low, only $50 \mathrm{~kg} / \mathrm{h}-100 \mathrm{~kg} / \mathrm{h}$, the variation of thermal efficiency with a small 
range of mass flow rate which varies from $53 \mathrm{~kg} / \mathrm{h}$ to $250 \mathrm{~kg} / \mathrm{h}$ was simulated in the numerical study, although the simulation with a large range could also be conducted.

\section{Conclusions}

An experimental platform for testing thermal performance of a water/steam cavity receiver was designed and built. The electrical heating mode was chosen to simulate the non-uniform distribution of heat flux on the surface of absorber tubes. The start-up curves under different operating pressures were obtained and the results have shown that the receiver has low thermal efficiency, only $56 \%-70 \%$, even in steady operating status. The low thermal efficiency is attributed to the low mass flow rate. In order to find an appropriate mass flow rate for the receiver to ensure its efficient operation, a computational model was established and the receiver was studied numerically. The numerical results are in good agreement with the experimental results. The curve of thermal efficiency versus a small range of mass flow rate which varies from $53 \mathrm{~kg} / \mathrm{h}$ to $250 \mathrm{~kg} / \mathrm{h}$ was obtained. The result indicates that the thermal efficiency increases with increasing mass flow rate. For the receiver studied in the present study, the appropriate mass flow rate recommended for making the thermal efficiency reach a value of about $85 \%$ like in the CESA-1 unit is at least $200 \mathrm{~kg} / \mathrm{h}$.

\section{Acknowledgments}

The present work was supported by the National Basic Research Program of China (2010CB227102) and National Natural Science Foundation of China (No. 51121092).

\section{References}

1. Wang, Z.F.; Chang, C.; Tong, C.H. Advances in International CSP Technologies; Joint Laboratory of Chinese Academy of Sciences Engineering Thermophysics Institution and Huang Ming Group: Beijing, China, 2004; pp. 3-6.

2. Clausing, A.M. An analysis of convective losses from cavity solar central receiver. Sol. Energy 1981, 27, 295-300.

3. Clausing, A.M. Convective losses from cavity solar receivers-comparisons between analytical predictions and experimental results. J. Sol. Energy Eng. 1983, 105, $29-33$.

4. Behnia, M.; Reizes, G.D. Combined radiation and natural-convection in a rectangular cavity with a transparent wall and containing a non-participating fluid. Int. J. Numer. Methods Fluids 1990, 10, 305-325.

5. Ramesh, N.; Venkateshan, S.P. Effect of surface radiation on natural convection in a square enclosure. J. Thermophys. Heat Transf. 1999, 13, 299-301.

6. Taumoefolau, T.; Paitoonsurikarn, S.; Hughes, G.; Lovegrove, K. Experimental investigation of natural convection heat loss from a model solar concentrator cavity receiver. J. Sol. Energy Eng. Trans. ASME 2004, 126, 801-807.

7. Sendhil, K.N.; Reddy, K.S. Numerical investigation of natural convection heat loss in modified cavity receiver for fuzzy focal solar dish concentrator. Sol. Energy 2007, 81, 846-855. 
8. Le Quere, P.; Humphery, J.A.; Sherman, F.S. Numerical calculation of thermally driven two-dimensional unsteady laminar flow in cavities of rectangular cross section. Numer. Heat Transf. 1981, 4, 249-283.

9. Le Quere, P.; Penot, F.; Mirenayat, M. Experimental Study of Heat Loss through Natural Convection from an Isothermal Cubic Open Cavity; Technical Report; SAND81-8014; Sandia National Laboratories: Albuquerque, NM, USA, 1981.

10. Reynolds, D.J.; Jance, M.J.; Behnia, M.; Morrison, G.L. An experimental and computational study of the heat loss characteristics of a trapezoidal cavity absorber. Sol. Energy 2004, 76, 229-234.

11. Prakash, M.; Kedare, S.B.; Nayak, J.K. Investigations on heat losses from a solar cavity receiver. Sol. Energy 2009, 83, 157-170.

12. Paitoonsurikarn, S.; Lovegrove, K.; Hughes, G.; Pye, J. Numerical investigation of natural convection loss from cavity receivers in solar dish applications. J. Sol. Energy Eng. 2011, 133, 021004:1-021004:10.

13. Dehghan, A.A.; Behnia, M. Combined natural convection-conduction and radiation heat transfer in a discretely heated open cavity. Trans. ASME 1996, 118, 56-64.

14. Baker, A.F.; Faas, S.E.; Radosevich, L.G.; Skinrood, A.C. U.S.-Spain Evaluation of the Solar One and CESA-1 Receiver and Storage Systems; Technical Report; SAND88-8262; Sandia National Laboratories: Albuquerque, NM, USA, 1989.

15. Fang, J.B.; Wei, J.J.; Dong, X.W.; Wang, Y.S. Thermal performance simulation of a solar cavity receiver under windy conditions. Sol. Energy 2011, 85, 126-138.

16. Fan, Q.G. Principles of Boiler, 1st ed.; China Electric Power Press: Beijing, China, 2008; pp. 300-308.

17. Modest, M.F. Radiative Heat Transfer; McGraw-Hill: Columbus, OH, USA, 1993; pp. 644-676.

18. Kandlikar, S.G. A general correlation for saturated two-phase flow boiling heat transfer inside horizontal and vertical tubes. J. Heat Transf. 1990, 112, 219-228.

19. Kandlikar, S.G. Development of a flow boiling map for subcooled and saturated flow boiling of different fluids inside circular tubes. J. Heat Transf. 1991, 113, 190-200.

20. Hsu, Y.Y. On the size range of active nucleation cavities on a heating surface. J. Heat Transf. 1962, 84, 207-216.

(C) 2013 by the authors; licensee MDPI, Basel, Switzerland. This article is an open access article distributed under the terms and conditions of the Creative Commons Attribution license (http://creativecommons.org/licenses/by/3.0/). 